\title{
MAP kinase subtypes and Akt regulate diosgenin-induced apoptosis of rheumatoid synovial cells in association with COX-2 expression and prostanoid production
}

\author{
BERTRAND LIAGRE ${ }^{1}$, DAVID Y. LEGER ${ }^{1}$, PASCALE VERGNE-SALLE $^{2}$ and JEAN LOUIS BENEYTOUT ${ }^{1}$ \\ ${ }^{1}$ Laboratoire de Biochimie, UPRES EA 4021, Faculté de Pharmacie, 87025 Limoges Cedex; \\ ${ }^{2}$ Service de Rhumatologie et Thérapeutique, CHRU Dupuytren, 87042 Limoges Cedex, France
}

Received May 26, 2006; Accepted July 11, 2006

\begin{abstract}
In the present study, we investigated the signalling pathways involved in diosgenin-induced apoptosis in human rheumatoid arthritis (RA) fibroblast-like synoviocytes (FLS) in vitro with particular interest on Akt and MAPKs activation in relation to arachidonic acid metabolism via COX-2 pathway. MAPK activation was measured by ELISA quantification in diosgenin-treated human RA FLS. Expression of Akt and phospho-Akt was analyzed by Western blot analysis. Nuclear factor- $\kappa \mathrm{B}(\mathrm{NF}-\kappa \mathrm{B})$ translocation was evaluated by electromobility shift assay. The prostanoid production (COX-2 activity) was measured by quantitative ELISA. Diosgenininduced apoptosis in the presence of MAPK or Akt inhibitors was detected by a quantitative determination of DNA fragmentation. Treatment of human RA FLS with $40 \mu \mathrm{M}$ diosgenin caused an activation of p38 and JNK and an inhibition of ERK phosphorylation. Akt and NF- $\mathrm{KB}$ are potentially required for diosgenin-induced apoptosis in human RA FLS because $40 \mu \mathrm{M}$ diosgenin abrogated Akt phosphorylation which correlated with an inhibition of NF-кB nuclear translocation. SB203580 and SP600125 (p38 and JNK inhibitors) reduced diosgenininduced DNA fragmentation whereas U0126 and LY294002
\end{abstract}

Correspondence to: Dr Bertrand Liagre, Laboratoire de Biochimie, UPRES EA 4021, Faculté de Pharmacie, 2 rue du Docteur Marcland, 87025 Limoges Cedex, France

E-mail: bertrand.liagre@unilim.fr

Abbreviations: RA, rheumatoid arthritis; FLS, fibroblast-like synoviocytes; MAPK, mitogen-activated protein kinase; ERK, extracellular signal-regulated kinase; JNK, c-jun $\mathrm{NH}_{2}$-terminal kinase; $\mathrm{NF}-\kappa \mathrm{B}$, nuclear factor-кB; COX, cyclooxygenase; mPGES, microsomal prostaglandin E synthase; $\mathrm{PG}$, prostaglandin; IL, interleukin; DMEM, Dulbecco's modified Eagle's medium; FCS, fetal calf serum; NSAIDs, non-steroidal anti-inflammatory drugs; DMARDs, disease modifying antirheumatic drugs; ELISA, enzyme-linked immunosorbent assay; EMSA, electromobility shift assay; DIG, digoxigenin; TLDA, TaqMan ${ }^{\circledR}$ low-density array; OD, optical density

Key words: human synoviocytes, diosgenin, apoptosis, MAP kinases, Akt, cyclooxygenase-2
(MEK and PI3 kinase/Akt inhibitors) caused an amplification of proapoptotic effect of diosgenin. Diosgenin increased COX-2 activity resulting in $\mathrm{PGE}_{2}$ and 6-keto- $\mathrm{PGF}_{1 \alpha}$ overproduction in human RA FLS. All MAPK inhibitors markedly reduced diosgenin-induced $\mathrm{PGE}_{2}$ and 6-keto- $\mathrm{PGF}_{1 \alpha}$ synthesis except for SP600125 on 6-keto-PGF ${ }_{1 \alpha}$ production. These results provide, for the first time, strong evidence that a combined association implicating a MEK inhibitor (U0126) and diosgenin is the most effective in inducing very strong apoptosis with down-regulation of COX-2 expression and activity in human RA FLS.

\section{Introduction}

Apoptosis is considered to be one of the mechanisms regulating autoimmune diseases such as rheumatoid arthritis (RA) (1). In the pathogenesis of RA, it is thought that the normal balance between proliferation and apoptosis of synovial fibroblasts is lost, leading to hyperplasia of these fibroblasts (2). Activated synovial cells cause growth of synovium in the articular cavity along with angiogenesis, invade the adjacent bone, promote production of inflammatory mediators by inflammatory cells, and cause cartilage and bone destruction (3). Therefore, it has been shown that stimulation of apoptosis in synovial fibroblasts might be useful for the treatment of RA $(4,5)$.

Mitogen-activated protein kinases (MAPKs) are key proteins regulating the apoptotic process. MAPKs are proline-directed protein kinases that mediate the effects of numerous extracellular stimuli in a wide array of biological processes, such as cellular proliferation, differentiation and death. Three groups of mammalian MAPKs have been studied in detail: extracellular signal-regulated kinases (ERKs) (6), c-jun $\mathrm{NH}_{2}$-terminal kinases (JNKs) and p38 MAPKs (7). MAPKs are activated by upstream dual-specificity kinases through phosphorylation on both threonine and tyrosine residues at the Thr-Xaa-Tyr dual phosphorylation motif $(8,9)$. All three MAPK families have been implicated in RA (10).

Another key protein that modulates the apoptotic response is Akt. Akt kinase, a downstream target of PI3 kinase, is a key serine/threonine kinase in growth factor-mediated inhibition of apoptosis (11). Molecular studies have revealed that Akt activation inhibits apoptosis in rheumatoid synovial cells $(12,13)$. 
Recently, we have shown for the first time that a plant steroid, diosgenin, inhibited the growth of human RA fibroblast-like synoviocytes (FLS) with apoptosis induction characterized by a loss of mitochondrial membrane potential, caspase-3 activation and DNA fragmentation (14). Furthermore, the proapoptotic effect of diosgenin was associated with overexpression of cyclooxygenase-2 (COX-2) correlated with overproduction of endogenous prostaglandin $\mathrm{E}_{2}\left(\mathrm{PGE}_{2}\right)$ (14).

The aim of this study was to investigate the signalling pathways involved in diosgenin-induced apoptosis in human RA FLS in vitro. We particularly focused our attention on Akt and MAPK activation in relation to arachidonic acid metabolism via the COX-2 pathway in apoptotic conditions. Our results demonstrate diosgenin-induced apoptosis through a combined activation of p38 and JNK with an inhibition of ERK and Akt pathways. Furthermore, pre-treatment with a MEK inhibitor amplified diosgenin-induced apoptosis with a significant decrease in COX-2 expression and prostanoid production in human RA FLS.

\section{Materials and methods}

Materials. Dulbecco's modified Eagle's medium (DMEM), fetal calf serum (FCS) and penicillin-streptomycin were supplied by Gibco-BRL (Cergy Pontoise, France). Collagenase was obtained from Worthington Biochemical Corporation (Halls Mill Road, Freehold, NJ, USA). Dispase, hyaluronidase, DNase I, diosgenin and human $B$-actin antibody were purchased from Sigma (Saint Quentin Fallavier, France). Recombinant human IL-1ß, human phospho-ERK1/ERK2, phospho-JNK and phospho-p38 $\alpha$ DuoSet IC ELISA and 15-d-PGJ 2 immunoassay were purchased from R\&D Systems (Lille, France). Human COX-2, Akt and phospho-Akt antibodies were purchased from Santa Cruz Biotechnology (Tebu-Bio, Le Perray en Yvelines, France). SB203580, SP600125, U0126 and LY294002 were purchased from Calbiochem (VWR, Fontenay-sous-Bois, France). ELISA kits for prostanoids and human mPGES-1 antibody were purchased from Cayman Chemical (SpiBio, Massy, France). Cell death detection ELISA $^{\text {PLus }}$ and DIG Gel Shift Kit were supplied by Roche Diagnostics (Meylan, France).

Preparation of human synovial cells. RA synoviocytes were isolated from fresh synovial biopsies obtained from six RA patients undergoing hip arthroplasty. All patients fulfilled the 1987 American Rheumatism Association criteria for RA (15). The mean age of the patients was 63.8 2 2.9 years (range 6067 years). The mean disease duration was $8.3 \pm 2.8$ years. At the time of surgery, the disease activity score (DAS 28) was greater than 3.2. These activities were approved by local institutional review boards, and all subjects gave written informed consent. Synovia were minced and digested with $1.5 \mathrm{mg} / \mathrm{ml}$ collagenase-dispase, $1 \mathrm{mg} / \mathrm{ml}$ hyaluronidase and $0.15 \mathrm{mg} / \mathrm{ml}$ DNase I for $3-4 \mathrm{~h}$ at $37^{\circ} \mathrm{C}$ as previously described (16). After centrifugation, cells were resuspended in DMEM supplemented with $10 \%$ FCS, $4.5 \mathrm{~g} / 1 \mathrm{D}$-glucose, $25 \mathrm{mM}$ HEPES, $100 \mathrm{U} / \mathrm{ml}$ penicillin and $100 \mu \mathrm{g} / \mathrm{ml}$ streptomycin (Gibco-BRL) in a humidified atmosphere containing 5\% (v/v) $\mathrm{CO}_{2}$ at $37^{\circ} \mathrm{C}$.
After $48 \mathrm{~h}$, non-adherent cells were removed. Adherent cells [macrophage-like and fibroblast-like synoviocytes (FLS)] were cultured in complete medium and, at confluence, cells were trypsinized and only FLS were passed. These cells were used between passages 4 and 8 when they morphologically resembled FLS after indirect immunofluorescence study. RA FLS were cultured 45-60 days prior to experimentation. This delay eliminated all possible interactions resulting from an eventual pre-operative treatment (NSAIDs, analgesics, DMARDs or steroids).

Culture of human RA FLS. RA FLS were trypsinized between passages 4 and 8 . Cell count and viability were determined and cells were plated in culture plates or flasks (Sarstedt, Orsay, France). Viability, measured by trypan blue dye exclusion at the start and the end of culture, was always greater than $95 \%$. RA FLS $\left(10^{5}\right)$ from RA patients were used for indirect immunofluorescence as previously described (14).

For all experiments, RA FLS were allowed to adhere and grow for $48 \mathrm{~h}$ in culture medium prior to exposure to $40 \mu \mathrm{M}$ diosgenin because we had previously demonstrated that this concentration induced strong apoptosis of human RA FLS (14). A stock solution of $10^{-2} \mathrm{M}$ diosgenin was prepared in ethanol and diluted in culture medium to give a final concentration of $40 \mu \mathrm{M}$. The same amount of ethanol $(<0.5 \%)$ was added to control cells. After treatment, culture medium was not changed during the entire study.

Quantification of human phospho-ERK1/ERK2, phospho-JNK and phospho-p38a. Human RA FLS were grown in $25 \mathrm{~cm}^{2}$ tissue culture flasks for $48 \mathrm{~h}$ before treatment. After washing with PBS (pH 7.4), cells were incubated at $37^{\circ} \mathrm{C}$ with $40 \mu \mathrm{M}$ diosgenin for $20 \mathrm{~min}, 1 \mathrm{~h}, 6 \mathrm{~h}$ and $24 \mathrm{~h}$ or with interleukin (IL)-1ß (1 ng/ml) alone for $20 \mathrm{~min}$ as a positive control. After treatment, $10^{6}$ cells were homogenized in lysis buffer in accordance with the manufacturer's protocol (R\&D Systems). Before assay, one plate was coated with $100 \mu 1$ per well of capture antibody $(4 \mu \mathrm{g} / \mathrm{ml})$ overnight at room temperature. The plate was washed three times with $400 \mu 1$ wash buffer and blocked by adding $300 \mu \mathrm{l}$ blocking buffer to each well for 1-2 $\mathrm{h}$ at room temperature. Before use, cell lysates were centrifuged at $2000 \mathrm{~g}$ for $5 \mathrm{~min}$ and supernatants were diluted 6-fold. Phospho-ERK1/ERK2, phospho-JNK or phospho-p38 $\alpha$ detection was performed according to the manufacturer's instructions (R\&D Systems) as previously described (17).

Effect of diosgenin on Akt phosphorylation. Human RA FLS were cultured in $75 \mathrm{~cm}^{2}$ tissue culture flasks for $48 \mathrm{~h}$ before treatment. After $40 \mu \mathrm{M}$ diosgenin treatment for $24 \mathrm{~h}$, adherent cells were trypsinized and Western blot analysis was performed as previously described (18) using Akt, phospho-Akt (Thr 308) (Tebu-Bio) and $B$-actin antibodies (Sigma) and secondary antibodies conjugated with peroxidase (Dako). Blots were visualized using enhanced chemiluminescence reagents (Amersham Biosciences) and immediately exposed to X-ray film.

$N F-\kappa B$ nuclear translocation. NF-кB nuclear translocation was evaluated by electromobility shift assay (EMSA). Human RA FLS were grown in $75 \mathrm{~cm}^{2}$ tissue culture flasks for $48 \mathrm{~h}$ 
before treatment. After washing with PBS ( $\mathrm{pH} 7.4$ ), cells were incubated at $37^{\circ} \mathrm{C}$ with or without $40 \mu \mathrm{M}$ diosgenin for $24 \mathrm{~h}$. EMSA experiments were performed using DIG Gel Shift Kit (Roche Diagnostics). Briefly, cells were harvested, washed in cold PBS and resuspended in lysis buffer $(10 \mathrm{mM}$ HEPES pH 7.9, $1.5 \mathrm{mM} \mathrm{MgCl}_{2}, 10 \mathrm{mM} \mathrm{KCl}, 0.5 \mathrm{mM}$ dithiothreitol, 0.2 mM PMSF, protease inhibitors Complete $^{\mathrm{TM}}$ Mini, $0.5 \%$ Nonidet P-40). Nuclei were pelleted (2000 g, $10 \mathrm{~min}$ at $\left.4^{\circ} \mathrm{C}\right)$ and resuspended in nuclear extraction buffer $(20 \mathrm{mM}$ HEPES pH 7.9, $420 \mathrm{mM} \mathrm{NaCl}, 1.5 \mathrm{mM} \mathrm{MgCl}_{2}, 10 \mathrm{mM} \mathrm{KCl}$, $15 \%$ glycerol, $0.2 \mathrm{mM}$ EDTA, $0.5 \mathrm{mM}$ dithiothreitol, $0.2 \mathrm{mM}$

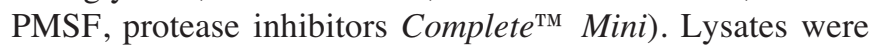
clarified by centrifugation $\left(13000 \mathrm{~g}, 10 \mathrm{~min}\right.$ at $\left.4^{\circ} \mathrm{C}\right)$ and supernatants were collected. The protein level was determined by the Bradford method and $10 \mu \mathrm{g}$ nuclear proteins were incubated with digoxigenin (DIG) labelled NF-кB probe (19) according to the manufacturer's protocol. The samples were loaded on a $5 \%$ native polyacrylamide gel, and run in $0.5 \mathrm{X}$ TBE buffer. Nuclear proteins and oligonucleotide-protein complexes were then electroblotted to Nylon membranes and incubated with anti-DIG polyclonal sheep antibody conjugated with alkaline phosphatase. Gel mobility shift was visualized after incubation with $\mathrm{CSPD}^{\circledR}$ chemiluminescence reagent and exposition to X-ray film.

mRNA and protein COX-2 expression analysis. Total RNA was extracted from cells cultured in $10 \%$ FCS medium without or with diosgenin $(40 \mu \mathrm{M})$ for $24 \mathrm{~h}$ by RNeasy Mini Kit (Qiagen, Courtaboeuf, France) according to the manufacturer's instructions. For other conditions, cells were pre-treated for $2 \mathrm{~h}$ with $10 \mu \mathrm{M}$ SB203580 (p38 inhibitor) or $10 \mu \mathrm{M}$ SP600125 (JNK inhibitor) or $10 \mu \mathrm{M}$ U0126 (MEK inhibitor) before addition of $40 \mu \mathrm{M}$ diosgenin for $24 \mathrm{~h}$. RNA purity and integrity were assessed on the Agilent 2100 bioanalyzer with the RNA 6000 Nano LabChip ${ }^{\circledR}$ reagent set (Agilent Technologies), and quantified spectrophotometrically. Expression of COX-2 gene was determined by a TaqMan low-density array (TLDA) based on an Applied Biosystems 7900HT Micro Fluidic Card (20). We used this technique to screen many genes including cytokines and metalloproteinases but, for this study, we concentrated specifically on COX-2 expression.

cDNA synthesis was performed with the High Capacity cDNA Archive Kit from Applied Biosystems according to the manufacturer's instructions. The TaqMan probe and primer sets for human COX-2 and glyceraldehyde 3-phosphate dehydrogenase (GAPDH) as a reference gene were carefully selected from pre-designed TaqMan Gene Expression Assays (Applied Biosystems). The exact locations and the sequences of the oligonucleotides used can be downloaded from the Applied Biosystems website by selecting the Assays IDs (Hs00153133_m1 for COX-2 and Hs99999905_m1 for GAPDH). We mixed $20 \mu 1$ of single-stranded cDNA (equivalent to $100 \mathrm{ng}$ of total RNA) with $30 \mu \mathrm{l}$ of nucleasefree water and $50 \mu 1$ of TaqMan Universal PCR Master Mix. After, we loaded $100 \mu 1$ of the sample-specific PCR mixture into 1 sample port, the cards were centrifugated twice for $1 \mathrm{~min}$ at $280 \mathrm{~g}$ and sealed to prevent well-to-well contamination. The cards were placed in the Micro Fluidic Card Sample Block of an ABI PRISM 7900HT Sequence Detection System (Applied Biosystems). Micro Fluidic Cards were analyzed with RQ documents and the RQ Manager software (SDS 2.2) for automated data analysis. Experiments, carried out in triplicate, were analyzed as 1 relative quantity (RQ) study. Expression values for COX-2 gene were normalized to the concentration of GAPDH which showed the least variation among reference genes in our primary cultured RA FLS model. COX-2 gene expression values were calculated based on the comparative threshold cycle method as previously described (20).

Furthermore, COX-2 and microsomal prostaglandin E synthase-1 (mPGES-1) expressions were realized by Western blot analysis using respectively human COX-2 (Tebu-Bio) and mPGES-1 (Cayman Chemical) antibodies.

Detection of prostanoid production. Human RA FLS were grown in $25 \mathrm{~cm}^{2}$ tissue culture flasks for $48 \mathrm{~h}$ before treatment. After washing with PBS ( $\mathrm{pH} 7.4$ ), cells were treated for $24 \mathrm{~h}$ at $37^{\circ} \mathrm{C}$ with $40 \mu \mathrm{M}$ diosgenin in DMEM containing $10 \%$ $(\mathrm{v} / \mathrm{v}) \mathrm{FCS}$ in a $5 \% \mathrm{CO}_{2}$ atmosphere. Prostanoid concentration in the medium was measured by ELISA according to the manufacturer's instructions and was normalized with respect to the number of viable cells present in the particular culture at the time of sampling. Other conditions included cells preincubated for $2 \mathrm{~h}$ with $10 \mu \mathrm{M} \mathrm{SB} 203580$ (p38 inhibitor) or $10 \mu \mathrm{M}$ SP600125 (JNK inhibitor) or $10 \mu \mathrm{M}$ U0126 (MEK inhibitor) prior to addition of $40 \mu \mathrm{M}$ diosgenin for $24 \mathrm{~h}$. These last conditions were tested only for $\mathrm{PGE}_{2}$ and 6-keto-PGF $\mathrm{PG}_{1 \alpha}$.

Apoptosis quantification:DNA fragmentation. Human RA FLS were cultured in 6 -well culture plates $\left(2 \times 10^{5}\right.$ cells/well $)$. Cells were treated without or with $40 \mu \mathrm{M}$ diosgenin alone for $24 \mathrm{~h}$, or pre-incubated for $2 \mathrm{~h}$ with $10 \mu \mathrm{M}$ SB203580 (p38 inhibitor), $10 \mu \mathrm{M}$ SP600125 (JNK inhibitor), $10 \mu \mathrm{M}$ U0126 (MEK inhibitor) or $20 \mu \mathrm{M}$ LY294002 (PI3 kinase/Akt inhibitor) before addition of $40 \mu \mathrm{M}$ diosgenin for $24 \mathrm{~h}$. Apoptosis was quantified on pooled cells (floating and adherent) using the 'cell death' ELISA (Cell Death Detection ELISA $^{\text {PLUS }}$, Roche Diagnostics). Cytosol extracts were obtained according to the manufacturer's protocol and apoptosis was measured as previously described (14).

Statistical analysis. The median and standard deviation (SD) were calculated using Excel (Microsoft Office, version 98). Statistical analysis of differences was carried out by analysis of variance (ANOVA) using StatView version 5.0 (SAS Institute Inc., Cary, NC). A P-value of $<0.05$ [Fisher's protected-least-significant-difference (PLSD) test] was considered to indicate significance.

\section{Results}

Activation of p38 and JNK and inhibition of ERK phosphorylation by diosgenin. It has been reported that $\mathrm{JNK} / \mathrm{p} 38$ MAPK and ERK play opposite roles in apoptosis induction in such a way that the former promotes apoptosis induction whereas the latter inhibits it. In order to elucidate potentially different actions of the three groups of MAPKs in human RA FLS, we studied diosgenin-triggered MAPK signal transduction cascades in relation to apoptosis induction. We showed that $40 \mu \mathrm{M}$ diosgenin activated p38 within $1 \mathrm{~h}$ in human RA FLS 
A

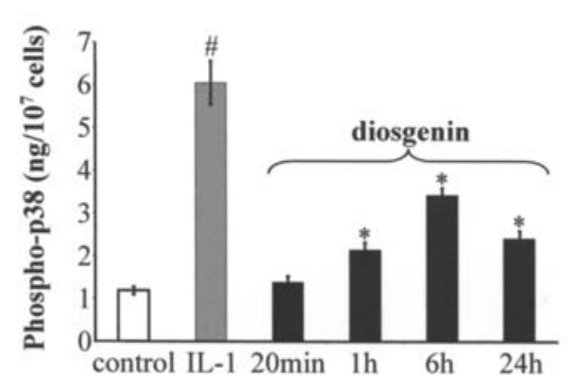

B

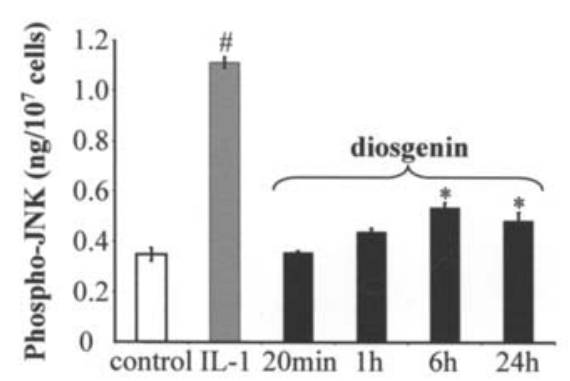

C

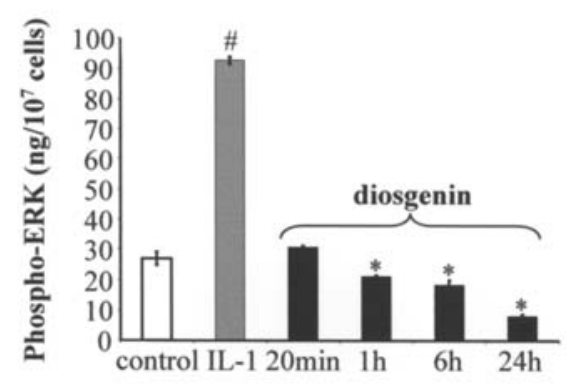

Figure 1. Activation of p38 (A) and JNK (B) and inhibition of ERK (C) phosphorylation by diosgenin. Human RA FLS were incubated without (control) or with $40 \mu \mathrm{M}$ diosgenin for $20 \mathrm{~min}, 1 \mathrm{~h}, 6 \mathrm{~h}$ and $24 \mathrm{~h}$ or with IL-13 $(1 \mathrm{ng} / \mathrm{ml})$ alone for $20 \mathrm{~min}$ as positive control. Cells were lysed and phosphorylated MAPKs were quantified with the DuoSet ${ }^{\circledR}$ IC assay kits (R\&D Systems). The respective DuoSet ${ }^{\circledR}$ IC assay kits contain the basic components required for the development of sandwich ELISAs to measure natural and recombinant phospho-ERK1 (T202/Y204) and phospho-ERK2 (T185/Y187), JNK1 and JNK2 dually phosphorylated at T183/Y185 and phospho-JNK3 (T221/Y223), and phospho-p38 $\alpha$ (T180/Y182) in cell lysates. RA FLS from three different patients were used for quantification. Data are expressed as mean $\pm \mathrm{SD}$ of three experiments. A representative experiment out of three is presented. A *P-value $<0.05$ and "P-value $<0.01$ (Fisher's PLSD test) were considered to indicate significance compared to untreated cell control.

$(+1.8$-fold versus control, $\mathrm{P}<0.05)$ with a maximum at $6 \mathrm{~h}$ $(+2.9$-fold versus control, $\mathrm{P}<0.05)$ and +2.0 -fold at $24 \mathrm{~h}$ versus control $(\mathrm{P}<0.05)$ (Fig. 1A). Furthermore, but more moderately, JNK phosphorylation increased 6 and $24 \mathrm{~h}$ after $40 \mu \mathrm{M}$ diosgenin treatment $(+1.4$ - and +1.3 -fold respectively versus control, $\mathrm{P}<0.05$ ) (Fig. 1B). In contrast, ERK phosphorylation decreased significantly over time in diosgenin-treated human RA FLS [-1.3-fold at $1 \mathrm{~h},-1.5$-fold at $6 \mathrm{~h}$ and was markedly inactivated at $24 \mathrm{~h}(-3.3$-fold) versus control, $\mathrm{P}<0.05]$ (Fig. 1C). IL-1 treatment for 20 min served as a positive control of MAPK activation.

Inhibition of survival factors Akt and $N F-\kappa B$ during diosgenininduced human RA FLS apoptosis. As diosgenin-induced
A

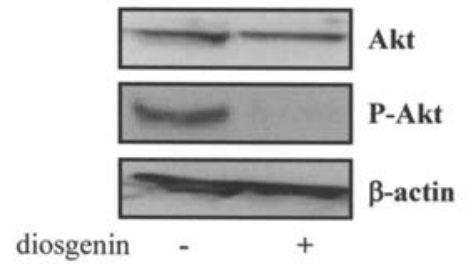

B

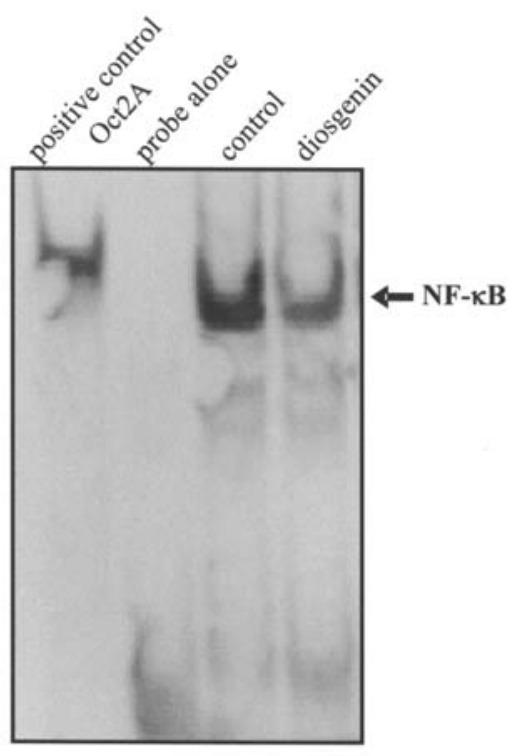

Figure 2. Down-regulation of survival factors after diosgenin-induced RA FLS apoptosis. Human RA FLS were treated or not with $40 \mu \mathrm{M}$ diosgenin for $24 \mathrm{~h}$. Total proteins were extracted and protein expression was evaluated by Western blotting. (A), Akt and phospho (P)-Akt (Thr 308) expression was estimated using rabbit polyclonal antibodies. Membranes were then reprobed with anti-ßB-actin antibody to ensure equal amounts of protein in each lane. (B), NF-kB nuclear translocation was evaluated by electromobility shift assay (EMSA). Human RA FLS were treated or not with $40 \mu \mathrm{M}$ diosgenin for $24 \mathrm{~h}$. Nuclear proteins were extracted and $10 \mu \mathrm{g}$ of each sample were subjected to EMSA using NF-kB consensus site DIG labeled probe and 'DIG Gel Shift Kit' (Roche Diagnostics). Complexes were visualized by autoradiography. Positive control, control factor Oct2A given by the manufacturer. The experiments were performed three times; representative results are shown.

apoptosis in human RA FLS (14), we examined Akt expression and $\mathrm{NF}-\kappa \mathrm{B}$ activation patterns in response to diosgenin treatment. We showed that although the expression of Akt remained stable after $40 \mu \mathrm{M}$ diosgenin treatment for $24 \mathrm{~h}$, Akt activity, reflected by its phosphorylation state, was totally abrogated (Fig. 2A). Furthermore, $40 \mu \mathrm{M}$ diosgenin-inhibited $\mathrm{NF}-\kappa \mathrm{B}$ activation at $24 \mathrm{~h}$ of treatment (Fig. 2B). These observations, inhibition of NF- $\mathrm{kB}$ translocation and phosphoAkt levels, led us to check whether the decrease in expression of these survival factors could be associated with an apoptotic phenomenon. This inhibition of NF- $\mathrm{KB}$ binding and phospho-Akt levels was correlated with apoptosis induced by diosgenin in human RA FLS.

Prostanoid production during diosgenin-induced human RA FLS apoptosis. Recently, we showed that diosgenin-induced apoptosis in synovial cells was associated with $\mathrm{PGE}_{2}$ overproduction. In order to clarify this point, we examined whether 

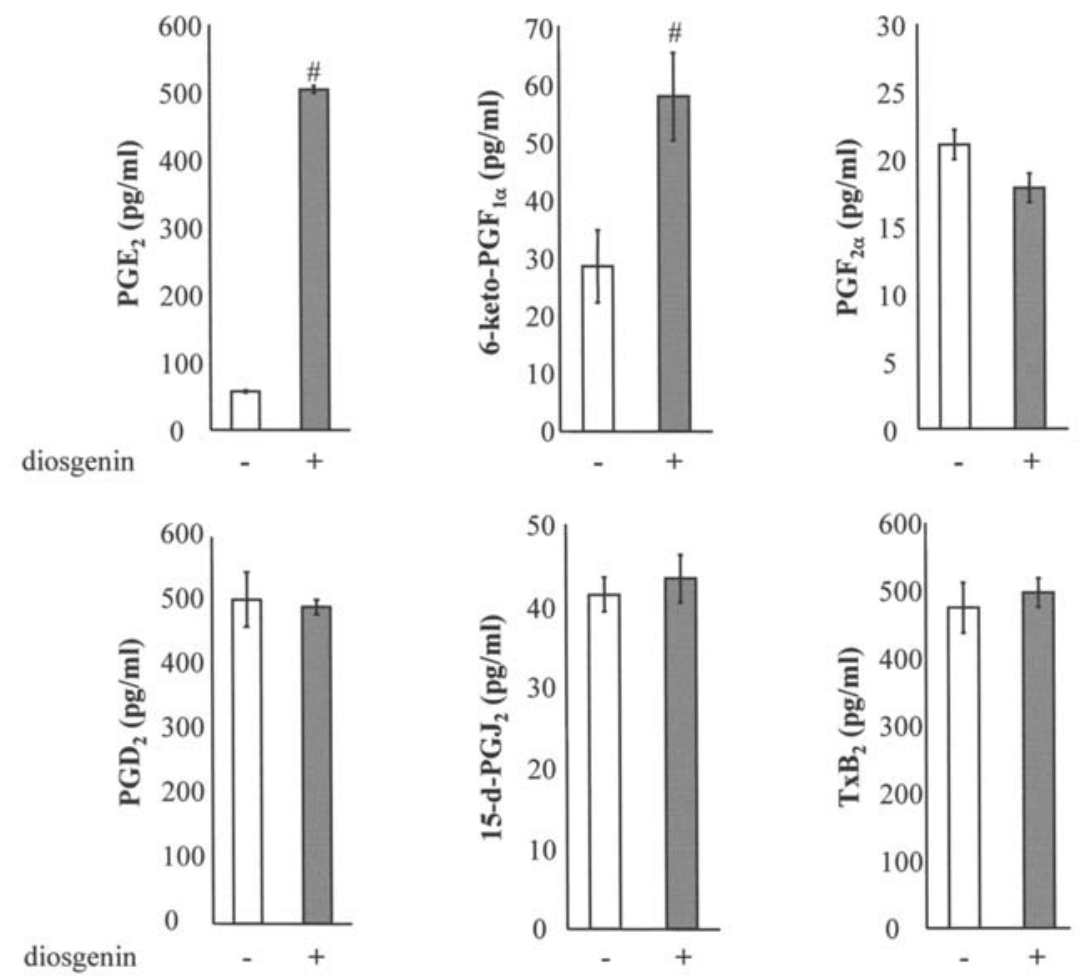

Figure 3. Production of prostanoids after diosgenin-induced RA FLS apoptosis. Cells were treated or not with $40 \mu \mathrm{M}$ diosgenin for $24 \mathrm{~h}$. The prostanoid concentration in the medium was measured by ELISA according to the manufacturer's instructions and was normalized with respect to the number of viable cells present in the particular culture at the time of sampling. Measurements were made on FLS from four different patients. Data are expressed as mean \pm SD of four experiments. A \#P-value $<0.01$ (Fisher's PLSD test) was considered to indicate significance compared to control (untreated cells).

or not the proapoptotic effect of diosgenin was associated with the synthesis of other prostanoids. After $40 \mu \mathrm{M}$ diosgenin treatment for $24 \mathrm{~h}$, only $\mathrm{PGE}_{2}$ and 6-keto- $\mathrm{PGF}_{1 \alpha}$ productions were increased (+8.9- and +2-fold respectively versus control, $\mathrm{P}<0.05)$ in apoptotic conditions. Diosgenin had no significant effect on $\mathrm{PGF}_{2 \alpha}, \mathrm{PGD}_{2}, 15-\mathrm{d}-\mathrm{PGJ}_{2}$ and $\mathrm{TxB}_{2}$ synthesis (Fig. 3).

Implication of MAPK pathway in regulation of $C O X-2$ expression and prostaglandin cascade by diosgenin in apoptotic conditions. Recent studies pointed out that inhibition of COX-2 expression is directly correlated with inhibition of the MAPK cascade in rheumatoid synovial cells and chondrocytes (21-23). Using an inhibitory strategy of MAPK activation, we studied the effect of diosgenin on COX-2 mRNA and protein expression but also on $\mathrm{PGE}_{2}$ and 6-keto-PGF $\mathrm{PG}_{1 \alpha}$ production in human RA FLS. As shown in Fig. 4A, under apoptotic conditions, $40 \mu \mathrm{M}$ diosgenin increased mRNA expression of COX-2 (+14-fold) compared to control cells. In the presence of MAPK inhibitors, pre-treatment with $10 \mu \mathrm{M}$ SB203580 (p38 inhibitor) for $2 \mathrm{~h}$ before addition of diosgenin decreased COX-2 expression by $-60 \%$ at the mRNA level compared to diosgenin alone. Pre-treatment with $10 \mu \mathrm{M}$ SP600125 (JNK inhibitor) or U0126 (MEK inhibitor) for $2 \mathrm{~h}$ before addition of diosgenin was less effective than SB203580 but also decreased COX-2 mRNA expression by $-31 \%$ and $-18 \%$ respectively compared to diosgenin alone (Fig. 4A). As previously described (14), $40 \mu \mathrm{M}$ diosgenin increased COX-2 protein levels compared to control cells (Fig. 4B). Inhibition of COX-2 protein expression by MAPK inhibitors is shown in Fig. 4B. Pre-treatment by each inhibitor before addition of diosgenin markedly reduced $\mathrm{COX}-2$ protein levels compared to diosgenin alone. mPGES-1 is a newly identified inducible enzyme of the arachidonic acid cascade with a key function in $\mathrm{PGE}_{2}$ synthesis. We examined whether or not mPGES-1 was implicated along with COX-2 in diosgenin-induced $\mathrm{PGE}_{2}$ synthesis. mPGES-1 expression in human RA FLS was not modified in the presence or absence of diosgenin (Fig. 4B).

As mentioned above, diosgenin only induced the production of $\mathrm{PGE}_{2}$ and 6-keto- $\mathrm{PGF}_{1 \alpha}$ compared to other prostanoids. As shown in Fig. 4C, diosgenin-induced $\mathrm{PGE}_{2}$ production was decreased by $-64 \%$, and 6 -keto- $\mathrm{PGF}_{1 \alpha}$ levels by $-54 \%$, by $10 \mu \mathrm{M}$ SB203580. Pre-treatment with $10 \mu \mathrm{M}$ SP600125 also decreased diosgenin-induced $\mathrm{PGE}_{2}$ production by $-58 \%$ but had no effect on diosgenin-induced 6-keto- $\mathrm{PGF}_{1 \alpha}$ production. However, the maximal inhibitory effect on diosgenin-induced prostaglandin production was observed using U0126. Indeed, $10 \mu \mathrm{M}$ U0126 decreased PGE $_{2}$ and 6-keto-PGF ${ }_{1 \alpha}$ levels by $-89 \%$ and $-86 \%$ respectively compared to diosgenin alone in human RA FLS (Fig. 4C).

Diosgenin-induced apoptosis in human RA FLS is directly related to MAPK and Akt pathways. MAPKs represent an attractive target for RA treatment because they can regulate cell proliferation and apoptosis. Furthermore, inhibition of Akt activation was demonstrated to induce apoptosis. In the present report, we investigated whether or not p38, JNK, ERK and Akt were implicated in the apoptotic signalling pathway of diosgenin in human RA FLS. We chose to study DNA fragmentation, a final step of apoptosis. Quantitative determination of cytoplasmic histone-associated-DNA- 
A

\begin{tabular}{cc}
\hline $\begin{array}{l}\text { Effect of MAPK inhibitors on COX -2 mRNA expression in diosgenin- } \\
\text { treated human RA FLS }\end{array}$ \\
\hline Conditions & Ratio (versus control cells) \\
\hline diosgenin & $14.7 \pm 1.2$ \\
SB203580+diosgenin & $5.8 \pm 0.9$ \\
SP600125+diosgenin & $10.2 \pm 1.1$ \\
U0126+diosgenin & $12.1 \pm 1.3$ \\
\hline
\end{tabular}

B
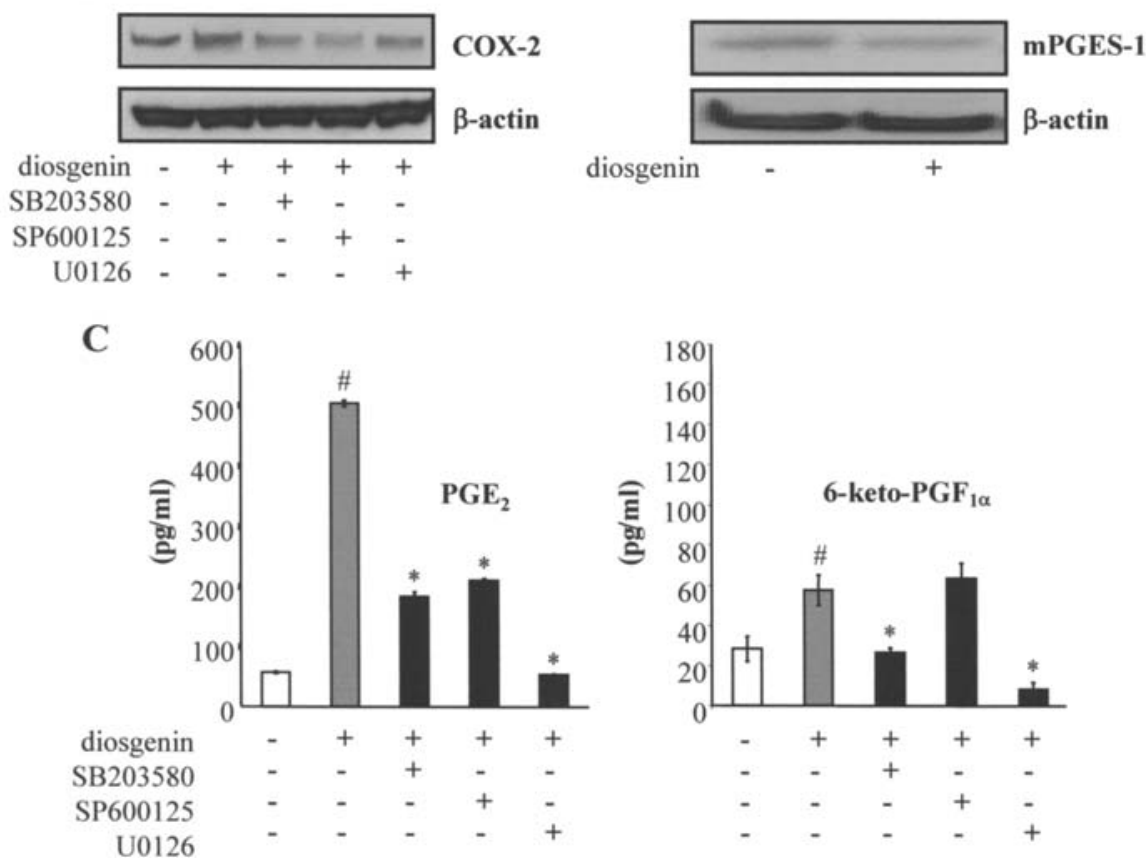

Figure 4. Involvement of MAPK pathway in the regulation of COX-2 expression and prostaglandin cascade in diosgenin-induced RA FLS apoptosis. (A), Total RNA was extracted from cells cultured in medium without or with diosgenin $(40 \mu \mathrm{M})$ for $24 \mathrm{~h}$ by RNeasy Mini Kit according to the manufacturer's instructions. For other conditions, cells were pre-treated for $2 \mathrm{~h}$ with $10 \mu \mathrm{M} \mathrm{SB} 203580$ (p38 inhibitor) or $10 \mu \mathrm{M} \mathrm{SP} 600125$ (JNK inhibitor) or $10 \mu \mathrm{M}$ U0126 (MEK inhibitor) before addition of $40 \mu \mathrm{M}$ diosgenin for $24 \mathrm{~h}$. Quantitative expression of COX-2 mRNA has been evaluated by a TaqMan low-density array (TLDA) based on an Applied Biosystems 7900HT Micro Fluidic Card. Micro Fluidic Cards were analyzed with RQ documents and the RQ Manager software (SDS 2.2) for automated data analysis. Experiments ( $\mathrm{n}=3$ ), carried out in duplicate, were analyzed as 1 relative quantity (RQ) study. Expression values for COX-2 gene were normalized to the concentration of GAPDH which showed the least variation among reference genes in our primary cultured RA FLS model. Data are presented as fold induction of COX-2 mRNA expression relative to the value for control culture (untreated cells). (B), Diosgenin-induced apoptosis up-regulated COX-2 but not mPGES-1 expression in human RA FLS. Protein extracts were obtained from cells cultured in medium without or with diosgenin $(40 \mu \mathrm{M})$ for $24 \mathrm{~h}$ and were subjected to Western blotting and cellular expressions of COX-2, mPGES-1 and B-actin were analyzed. For other conditions, cells were pre-treated for $2 \mathrm{~h}$ with $10 \mu \mathrm{M}$ SB203580 (p38 inhibitor) or $10 \mu \mathrm{M}$ SP600125 (JNK inhibitor) or $10 \mu \mathrm{M}$ U0126 (MEK inhibitor) before addition of $40 \mu \mathrm{M}$ diosgenin for $24 \mathrm{~h}$. Quantification of each band was performed by densitometry analysis software. One of three representative experiments is shown from three different patients. (C), Regulation of diosgenin-induced COX-2 activity by MAPK inhibitors. In the same conditions as previously described above, $\mathrm{PGE}_{2}$ and 6-keto-PGF ${ }_{1 \alpha}$ concentrations were measured in culture supernatants of human RA FLS by ELISA according to the manufacturer's instructions and were normalized with respect of the number of viable cells present in the particular culture at the time of sampling. Measurements were made on FLS from three different patients. Data are expressed as mean $\pm \mathrm{SD}$ of four experiments. A "P-value $<0.01$ and ${ }^{*} \mathrm{P}$-value $<0.05$ (Fisher's PLSD test) were considered to indicate significance compared to untreated cell control or diosgenin alone respectively.

fragments (mono- and oligonucleosomes) was performed by ELISA. Results showed that DNA fragmentation was reduced in human RA FLS pre-treated with inhibitors of transducing apoptotic factors (p38 and JNK) whereas it was amplified with inhibitors of survival transducers (ERK and Akt) (Fig. 5). Indeed, $10 \mu \mathrm{M} \mathrm{SB} 203580$ or SP600125 pre-treatment for $2 \mathrm{~h}$ before addition of diosgenin decreased DNA fragmentation of human RA FLS (-45\% and $-44 \%$ respectively versus diosgenin alone) in contrast to $10 \mu \mathrm{M}$ U0126 or $20 \mu \mathrm{M}$ LY294002 pretreatment which resulted in a synergistic effect with diosgenin to induce a higher apoptosis $(+83 \%$ and $+55 \%)$ than diosgenin alone.

\section{Discussion}

It is of great importance to understand the mechanisms of apoptosis in RA, as impaired apoptosis in synovial cells is closely associated with hyperplasia of synovial tissues found in patients with RA (24). Plant steroids have been thoroughly described for their pharmacological properties, including 


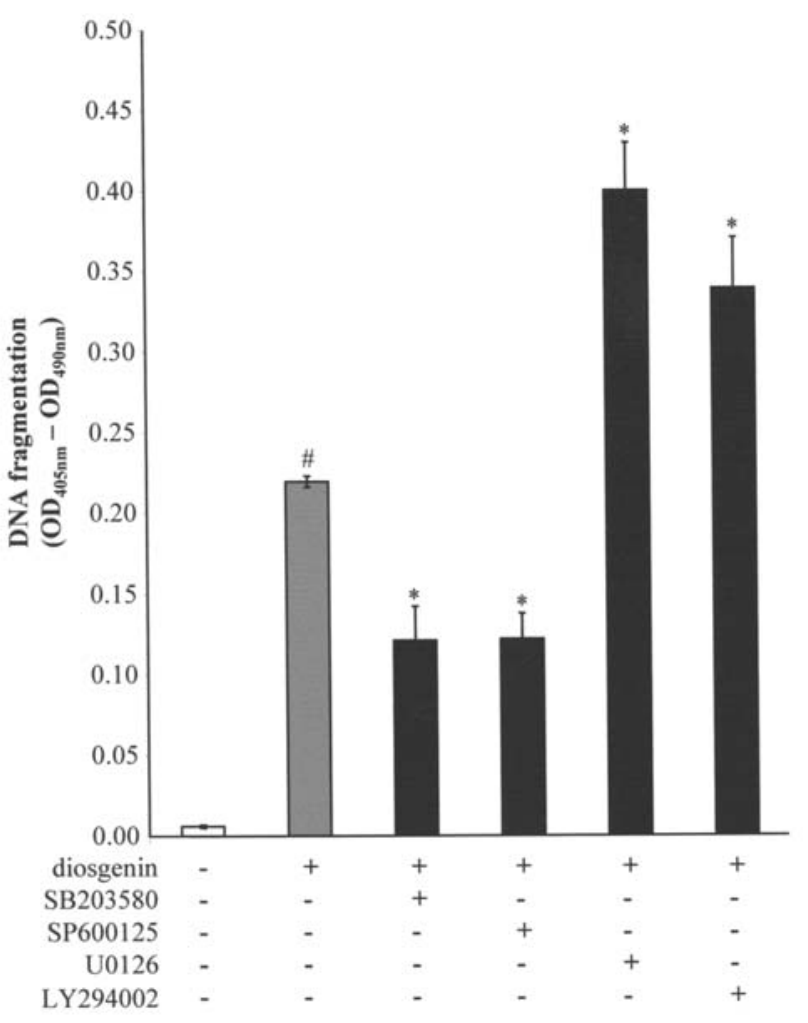

Figure 5. Different contribution of p38 and JNK pathways compared to ERK and Akt pathways on diosgenin-induced RA FLS apoptosis. Cells were treated without or with $40 \mu \mathrm{M}$ diosgenin alone for $24 \mathrm{~h}$, or pre-incubated for $2 \mathrm{~h}$ with $10 \mu \mathrm{M}$ SB203580 (p38 inhibitor), $10 \mu \mathrm{M}$ SP600125 (JNK inhibitor), $10 \mu \mathrm{M}$ U0126 (MEK inhibitor) or $20 \mu \mathrm{M}$ LY294002 (PI3 kinase/Akt inhibitor) before addition of $40 \mu \mathrm{M}$ diosgenin for $24 \mathrm{~h}$. Apoptosis was quantified on pooled cells (floating and adherent) by the cell death detection ELISA ${ }^{\text {PLUS }}$. Measurements were made on FLS from four different patients. Data are expressed as mean \pm $\mathrm{SD}$ of four experiments. A "P-value $<0.01$ and ${ }^{*} \mathrm{P}$-value $<0.05$ (Fisher's PLSD test) were considered to indicate significance compared to untreated cell control or diosgenin alone respectively.

hypocholesterolemic, antidiabetic and antioxidant activities. Particular attention has been given to their potential for cancer chemoprevention, especially as apoptosis inductors (25). Recently, we demonstrated that diosgenin-induced apoptosis in cancer cell lines (26-28). Furthermore, we described for the first time that diosgenin-induced apoptosis in human RA FLS with COX-2 overexpression (14).

It has been reported that JNK/p38 MAPK and ERK play opposite roles in apoptosis induction in such a way that the former promotes apoptosis induction whereas the latter inhibits it (29). Based on these data and our results, we studied the effect of diosgenin on the activation of survival (Akt, NF- $\mathrm{BB}$, ERK) or proapoptotic (p38, JNK) transducing factors in relation to diosgenin-induced COX-2 expression and activity in human RA FLS in vitro. MAPKs represent an attractive target for RA treatment because they can regulate cell proliferation, apoptosis (30), cytokine expression $(17,31)$ and metalloproteinase production (32). These MAPKs are expressed in synovial tissue and in cultured FLS $(10,33)$. In order to elucidate their different actions, we studied diosgenin-triggered MAPK signal transduction cascades in relation to apoptosis induction in human RA FLS. Treatment of cells with $40 \mu \mathrm{M}$ diosgenin caused an activation of p38 and JNK and an inhibition of ERK phosphorylation. IL-1 treatment, which is known to induce MAPK phosphorylation (34), served as a positive control. Recently, Yen et al (35) reported that diosgenin promoted angiogenesis in pre-osteoblast-like cells by a hypoxia-inducible factor- $1 \alpha$ dependent mechanism involving the activation of p38 MAPK. Our recent study showed that, diosgenin $(40 \mu \mathrm{M})$ inhibited ERK activation but activated p38 and JNK in human erythroleukemia (HEL) cells (28).

Survival factors such as Akt and NF-кB were also studied in diosgenin-induced apoptosis in human RA FLS. Akt is known to be activated in the rheumatoid synovial tissues (12) and is a master regulator of growth and survival. Recent studies have shown that Akt activation inhibits apoptosis in rheumatoid synovial cells $(12,13)$. Furthermore, PI3 kinase/Akt pathways have been reported to activate NF- $\mathrm{BB}$ in RA (36). In our study, Akt and NF- $\mathrm{KB}$ are potentially required for diosgenin-induced apoptosis in human RA FLS because $40 \mu \mathrm{M}$ diosgenin abrogated Akt phosphorylation which correlated with an inhibition of NF- $\mathrm{NB}$ nuclear translocation. In the recent work described above (35), the authors described also that diosgenin promoted angiogenesis by a mechanism involving the activation of Akt signalling pathway. It has also been shown that diosgenin inhibits osteoclastogenesis, invasion, and proliferation through the down-regulation of Akt, IкB kinase activation and NF-кB-regulated gene expression (37).

To confirm the implication of MAPK and Akt kinase signalling pathways in diosgenin-induced apoptosis in human RA FLS, we used specific inhibitors for pre-treatment before addition of diosgenin. After quantitative determination of cytoplasmic histone-associated-DNA-fragments (mono- and oligonucleosomes) with ELISA, our results showed that SB203580 (p38 inhibitor) and SP600125 (JNK inhibitor) reduced diosgenin-induced DNA fragmentation whereas U0126 (MEK inhibitor) and LY294002 (PI3 kinase/Akt inhibitor) caused an amplification of the proapoptotic effect of diosgenin. Taken together, these findings provide evidence that diosgenin $(40 \mu \mathrm{M})$ promotes apoptosis in human RA FLS by a mechanism involving p38 and JNK activation and inhibition of ERK and Akt signalling pathways.

RA is characterized by the proliferation of synoviocytes which also produce prostanoids. Eicosanoids and prostanoids are important lipid mediators that are produced at elevated levels in inflamed tissues including rheumatoid synovium and in cultured human RA FLS $(16,38,39)$. COX, which converts arachidonic acid into $\mathrm{PG}$ endoperoxides, is the rate limiting enzyme in prostanoid synthesis. It has been previously suggested that both $\mathrm{COX}-1$ and $\mathrm{COX}-2$ are expressed by human RA FLS and, in addition, the expression of COX-2 messager RNA and protein is enhanced by proinflammatory cytokines such as IL- $1 \beta$ and tumor necrosis factor- $\alpha$ (40). Our recent results demonstrated the fact that diosgenin can induce apoptosis in cancer cells $(26,27)$ and in human primary cultured synoviocytes (14) with COX-2 up-regulation. We have shown that selective inhibition of COX-2 activity with celecoxib diminished diosgenin-induced DNA fragmentation in human synoviocytes (14). Furthermore, increased $\mathrm{PGE}_{2}$ was shown to be related to apoptosis induction in growth plate chondrocytes (41) and, more recently, Pelletier et al (42) found that the in situ increase in chondrocyte death/apoptosis in experimental osteoarthritis was mainly caspase dependent and was influenced 


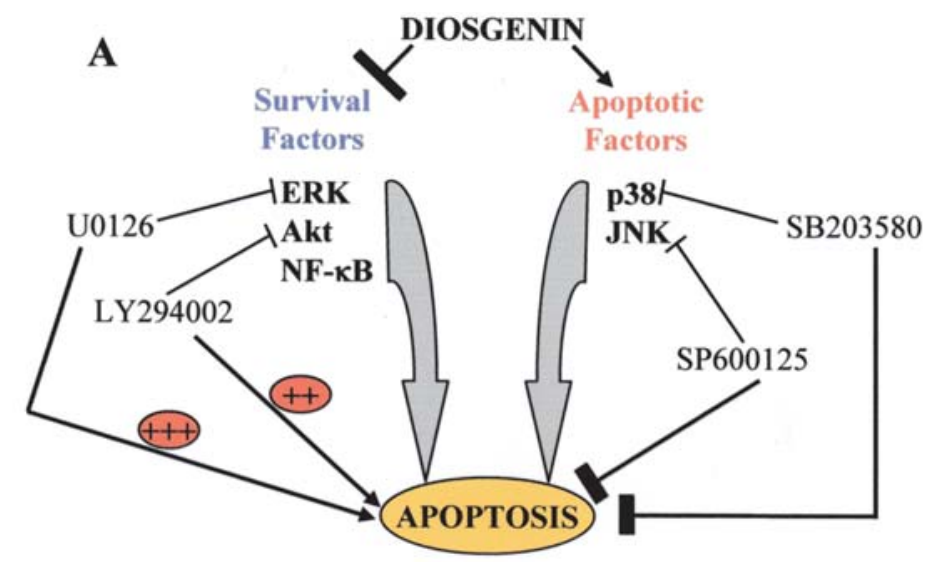

B
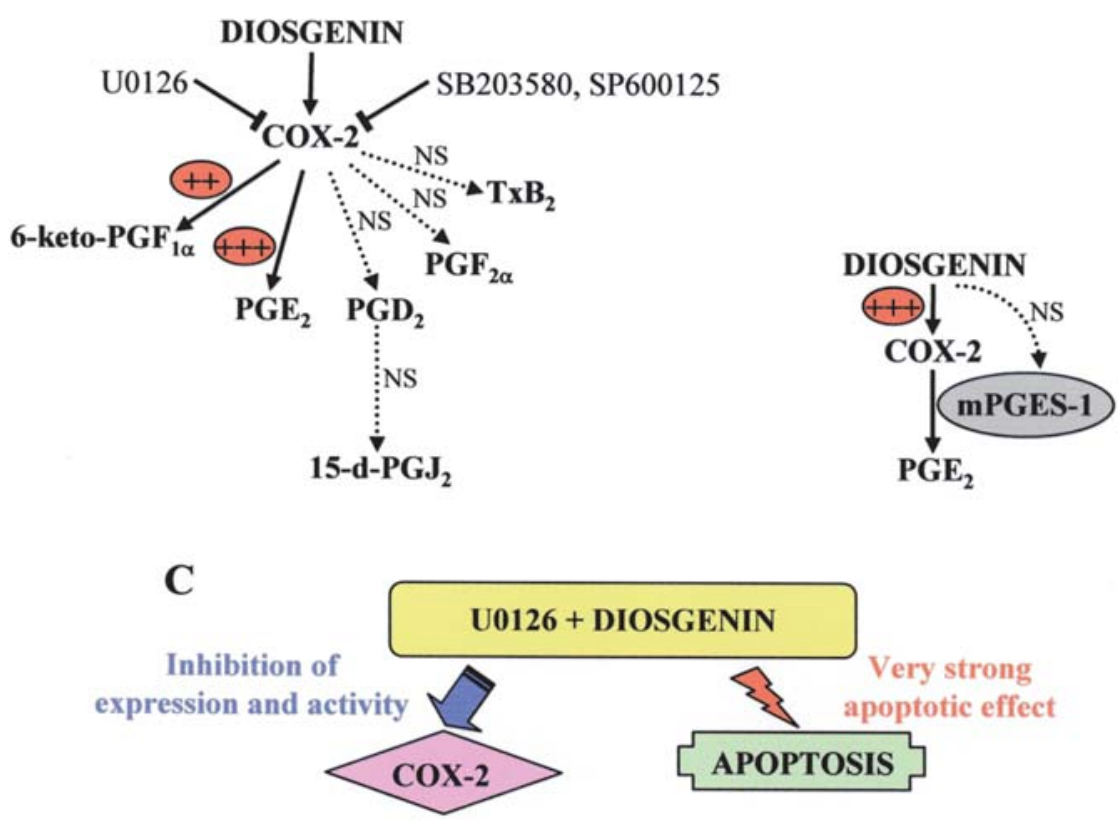

Figure 6. Schematic summary of signalling pathways involved in diosgenin-induced apoptosis associated with COX-2 up-regulation in human RA FLS in vitro. (A), Diosgenin-induced apoptosis in human RA FLS by inhibition of activation of survival transducing factors such as ERK, Akt and NF- $\mathrm{B}$ but also by activation of apoptotic transducers such as p38 and JNK. Pre-treatment with SB203580 or SP600125 (p38 or JNK inhibitors) before addition of diosgeninreduced diosgenin-induced apoptosis whereas pre-treatment with U0126 or LY294002 (MEK or PI3 kinase/Akt inhibitors) amplified the effect of diosgenin. (B), COX-2 up-regulation was correlated with diosgenin-induced apoptosis whereas mPGES-1 expression was not modified (NS, non-significant compared to untreated cells). Diosgenin $(40 \mu \mathrm{M})$ specifically induced the synthesis of $\mathrm{PGE}_{2}$ and 6-keto-PGF $\mathrm{P}_{1 \alpha}$ without modifying the production of other prostanoids ( $\mathrm{PGD}_{2}, 15-\mathrm{d}-\mathrm{PGJ}_{2}, \mathrm{PGF}_{2 \alpha}$ and $\mathrm{TxB}_{2}$; NS, non-significant compared to untreated cells). In our model, specific inhibitors of each MAPK reduced diosgenininduced COX-2 expression and activity. (C), This work demonstrates that a combined association implicating a MEK inhibitor (U0126) and diosgenin is the most efficient way in inducing very strong apoptosis with down-regulation of COX-2 expression and activity in human RA FLS.

by up-regulation of COX-2 levels. In synoviocytes, nitric oxide induced synoviocyte death through COX-2 expression and $\mathrm{PGE}_{2}$ synthesis with a significant change in mitochondrial membrane potential associated with caspase-3 activation (43). These results concerning the effects of nitric oxide are in agreement with our first study on the effects of diosgenin on RA FLS (14). All these reports have shown that the effects of COX-2 and related $\mathrm{PGE}_{2}$ in the regulation of apoptosis played an important role. Today, the connection between COX-2 expression and activation of the MAPK signalling pathway is well known. Recent studies pointed out that inhibition of COX-2 expression is directly correlated with inhibition of the MAPK cascade including p38 MAPK in rheumatoid synovial cells $(21,22)$. For this reason, our new investigations were focused on COX-2 in relation to the MAPK pathway during diosgenin-induced apoptosis in human RA FLS.

In the present study, we demonstrated that diosgenin increased COX-2 activity resulting in overproduction of $\mathrm{PGE}_{2}$ and 6-keto-PGF ${ }_{1 \alpha}$ in human RA FLS. However, production of other prostanoids such as $\mathrm{PGF}_{2 \alpha}, \mathrm{PGD}_{2}, 15-\mathrm{d}-\mathrm{PGJ}_{2}$ and $\mathrm{TxB}_{2}$ was not modified after diosgenin treatment. The cyclopentenone $\mathrm{PGJ}_{2}$ is formed within the cyclopentenone ring of endogenous $\mathrm{PGD}_{2}$ by a nonenzymatic reaction. $15-\mathrm{d}_{-}-\mathrm{PGJ}_{2}$ was released by human articular chondrocytes and found in joint synovial fluids taken from osteoarthritis or rheumatoid arthritis patients. It is well known today that $15-\mathrm{d}-\mathrm{PGJ}_{2}$ is implicated in the regulation of apoptosis induction. Indeed, $15-\mathrm{d}_{-}-\mathrm{PGJ}_{2}$-induced apoptosis of chondrocytes from osteo- 
arthritis or rheumatoid arthritis patients with an inhibition of NF- $\mathrm{KB}$ and activation of p38 MAPK (44). Our results showed that apoptosis induced by diosgenin $(40 \mu \mathrm{M})$ in human RA FLS inhibited NF-кB binding and activated p38 MAPK without increasing 15-d-PGJ ${ }_{2}$ synthesis. However, it has been recently shown that the NF-кB inhibitor BAY11-7085, a potent anti-inflammatory drug in rat adjuvant arthritis, induced apoptosis of chondrocytes and human synovial fibroblasts with a rapid and sustained phosphorylation of ERK (45). Further analysis in synovial fibroblasts showed that only molecules that suppressed BAY 11-7085-induced phosphorylation of ERK (i.e. 15-d-PGJ ${ }_{2}, \mathrm{PGD}_{2}$, and to a lesser extent, MEK inhibitor U0126, but not $\mathrm{PGE}_{2}$ and $\mathrm{PGF}_{2 \alpha}$ ) were able to protect cells from apoptosis (45). In diosgenin-induced apoptosis in human RA FLS, we showed that p38 inhibitor (SB203580), JNK inhibitor (SP600125) and MEK inhibitor (U0126) decreased diosgenin-induced COX-2 mRNA and protein expression. Furthermore, all inhibitors markedly reduced diosgenin-induced $\mathrm{PGE}_{2}$ and 6-keto- $\mathrm{PGF}_{1 \alpha}$ synthesis except for JNK inhibitor on 6-keto-PGF ${ }_{1 \alpha}$ production.

As we observed that, of all studied prostanoids, $\mathrm{PGE}_{2}$ was the principal one produced after diosgenin-induced apoptosis in human RA FLS, we analyzed the expression of mPGES-1. PGES-1, the enzyme converting COX-derived $\mathrm{PGH}_{2}$ into $\mathrm{PGE}_{2}$, exists in multiple forms with distinct enzymatic properties, modes of expression, subcellular localizations and intracellular functions. One of its isoforms, mPGES-1, is a perinuclear membrane-associated protein belonging to the microsomal glutathione S-transferase family. mPGES-1 is preferentially linked to inducible COX-2 and helps to stimulate $\mathrm{PGE}_{2}$ synthesis (46). mPGES-1 was recently shown to be a novel target for arthritis (47), and it is well described that mPGES-1 is expressed in human RA FLS (48), in rheumatoid synovium (49) and in RA synovial fluid mononuclear cells (50). In the present study, diosgenin did not induce mPGES-1 expression compared to untreated human RA FLS. Consequently, apoptosis induced by diosgenin is COX-2 dependent but mPGES-1 independent in our model of primary cultured human RA FLS.

In conclusion, based on our new investigations summarized in Fig. 6 and on our previous results (14), we showed that diosgenin-induced apoptosis in human RA FLS in vitro by inhibition of the activation of survival transducing factors such as ERK, Akt and NF-кB but also by activation of apoptotic transducers such as p38 and JNK. These results have been confirmed by using an inhibitory strategy on MAPK and Akt signalling. Pre-treatment with SB203580 or SP600125 (p38 or JNK inhibitors) before diosgenin addition reduced diosgenininduced apoptosis whereas pre-treatment with U0126 or LY294002 (MEK or PI3 kinase/Akt inhibitors) amplified the effect of diosgenin (Fig. 6A). On the other hand, we showed that diosgenin-induced apoptosis was correlated with COX-2 up-regulation whereas the expression of mPGES-1 was not modified (Fig. 6B). Diosgenin $(40 \mu \mathrm{M})$ specifically induced the synthesis of $\mathrm{PGE}_{2}$ and 6-keto- $\mathrm{PGF}_{1 \alpha}$ without modifying the production of other prostanoids $\left(\mathrm{PGD}_{2}, 15-\mathrm{d}-\mathrm{PGJ}_{2}, \mathrm{PGF}_{2 \alpha}\right.$ and $\mathrm{TxB}_{2}$ ). Furthermore, in our model, specific inhibitors of each MAPK reduced diosgenin-induced COX-2 expression and activity (Fig. 6B).
Taken together, these new results provide, for the first time, strong evidence that a combined association implicating a MEK inhibitor (U0126) and diosgenin is the most effective in inducing very strong apoptosis with down-regulation of COX-2 expression and activity in human RA FLS in vitro (Fig. 6C).

\section{Acknowledgements}

This study was supported by grants from La Société Française de Rhumatologie. The authors acknowledge Lionel Forestier for his excellent technical assistance for TLDA experiments and Dr Jeanne Cook-Moreau for helpful discussions in the preparation of this manuscript.

\section{References}

1. Thompson CB: Apoptosis in the pathogenesis and treatment of disease. Science 267: 1456-1462, 1995.

2. Perlman H, Pagliari LJ and Volin MV: Regulation of apoptosis and cell cycle activity in rheumatoid arthritis. Curr Mol Med 1: 597-608, 2001.

3. Firestein GS: Evolving concepts of rheumatoid arthritis. Nature 423: 356-361, 2003.

4. Nishioka K, Hasunuma T, Kato T, Sumida T and Kobata T: Apoptosis in rheumatoid arthritis: a novel pathway in the regulation of synovial tissue. Arthritis Rheum 41: 1-9, 1998.

5. Baier A, Meineckel I, Gay S and Pap T: Apoptosis in rheumatoid arthritis. Curr Opin Rheumatol 15: 274-279, 2003.

6. Davis RJ: The mitogen-activated protein kinase signal transduction pathway. J Biol Chem 268: 14553-14556, 1993.

7. Davis RJ: MAPKs: new JNK expands the group. Trends Biochem Sci 19: 470-473, 1994.

8. Cobb MH and Goldsmith EJ: How MAP kinases are regulated. J Biol Chem 270: 14843-14846, 1995.

9. Raingeaud J, Gupta S, Rogers JS, Dickens M, Han J, Ulevitch RJ and Davis RJ: Pro-inflammatory cytokines and environmental stress cause p38 mitogen-activated protein kinase activation by dual phosphorylation on tyrosine and threonine. J Biol Chem 270: 7420-7426, 1995.

10. Schett G, Tohidast-Akrad M, Smolen JS, et al: Activation, differential localization, and regulation of the stress-activated protein kinases, extracellular signal-regulated kinase, c-JUN $\mathrm{N}$-terminal kinase, and p38 mitogen-activated protein kinase, in synovial tissue and cells in rheumatoid arthritis. Arthritis Rheum 43: 2501-2512, 2000.

11. Dudek H, Datta SR, Franke TF, et al: Regulation of neuronal survival by the serine-threonine protein kinase Akt. Science 275: 661-665, 1997

12. Zhang HG, Wang Y, Xie JF, et al: Regulation of tumor necrosis factor alpha-mediated apoptosis of rheumatoid arthritis synovial fibroblasts by the protein kinase Akt. Arthritis Rheum 44: 1555-1567, 2001.

13. Miyashita T, Kawakami A, Tamai M, et al: Akt is an endogenous inhibitor toward tumor necrosis factor-related apoptosis inducing ligand-mediated apoptosis in rheumatoid synovial cells. Biochem Biophys Res Commun 312: 397-404, 2003.

14. Liagre B, Vergne-Salle P, Corbiere C, Charissoux JL and Beneytout JL: Diosgenin, a plant steroid, induces apoptosis in human rheumatoid arthritis synoviocytes with cyclooxygenase- 2 overexpression. Arthritis Res Ther 6: R373-R383, 2004.

15. Arnett FC, Edworthy SM, Bloch DA, et al: The American Rheumatism Association 1987 revised criteria for the classification of rheumatoid arthritis. Arthritis Rheum 31: 315-324, 1988.

16. Liagre B, Vergne P, Rigaud M and Beneytout JL: Expression of arachidonate platelet-type 12-lipoxygenase in human rheumatoid arthritis type B synoviocytes. FEBS Lett 414: 159-164, 1997.

17. Vergne-Salle P, Leger DY, Bertin P, Treves R, Beneytout JL and Liagre B: Effects of the active metabolite of leflunomide, A77 1726, on cytokine release and the MAPK signalling pathway in human rheumatoid arthritis synoviocytes. Cytokine 31: 335-348, 2005.

18. Leger DY, Liagre B and Beneytout JL: Role of MAPKs and NF-kappaB in diosgenin-induced megakaryocytic differentiation and subsequent apoptosis in HEL cells. Int J Oncol 28: 201-207, 2006 . 
19. Boyault S, Simonin MA, Bianchi A, et al: 15-Deoxy-delta12, 14-PGJ2, but not troglitazone, modulates IL-1B effects in human chondrocytes by inhibiting NF- $\mathrm{KB}$ and AP-1 activation pathways. FEBS Lett 501: 24-30, 2001

20. Langmann T, Mauerer R and Schmitz G: Human ATP-binding cassette transporter TaqMan low-density array: analysis of macrophage differentiation and foam cell formation. Clin Chem 52: 310-313, 2006.

21. Westra J, Limburg PC, De Boer P and van Rijswijk MH: Effects of RWJ 67657, a p38 mitogen activated protein kinase (MAPK) inhibitor, on the production of inflammatory mediators by rheumatoid synovial fibroblasts. Ann Rheum Dis 63: 1453-1459, 2004.

22. Fumimori T, Honda S, Migita K, et al: Erythromycin suppresses the expression of cyclooxygenase- 2 in rheumatoid synovial cells. J Rheumatol 31: 436-441, 2004.

23. Takahashi T, Ogawa Y, Kitaoka K, et al: Selective COX-2 inhibitor regulates the MAP kinase signaling pathway in human osteoarthritic chondrocytes after induction of nitric oxide. Int J Mol Med 15: 213-219, 2005.

24. Vaishnaw AK, McNally JD and Elkon KB: Apoptosis in the rheumatic diseases. Arthritis Rheum 40: 1917-1927, 1997.

25. Hibasami $\mathrm{H}$, Moteki $\mathrm{H}$, Ishikawa $\mathrm{K}$, et al: Protodioscin isolated from fenugreek (Trigonella foenumgraecum L.) induces cell death and morphological change indicative of apoptosis in leukemic cell line H-60, but not in gastric cancer cell line KATO III. Int J Mol Med 11: 23-26, 2003.

26. Moalic S, Liagre B, Corbiere C, Bianchi A, Dauca M, Bordji K and Beneytout JL: A plant steroid, diosgenin, induces apoptosis, cell cycle arrest and COX activity in osteosarcoma cells. FEBS Lett 506: 225-230, 2001

27. Leger DY, Liagre B, Corbiere C, Cook-Moreau J and Beneytout JL: Diosgenin induces cell cycle arrest and apoptosis in HEL cells with increase in intracellular calcium level, activation of cPLA2 and COX-2 overexpression. Int J Oncol 25: 555-562, 2004.

28. Liagre B, Bertrand J, Leger DY and Beneytout JL: Diosgenin, a plant steroid, induces apoptosis in COX-2 deficient K562 cells with activation of the p38 MAP kinase signalling and inhibition of NF-kappaB binding. Int J Mol Med 16: 1095-1101, 2005.

29. Xia Z, Dickens M, Raingeaud J, Davis RJ and Greenberg ME: Opposing effects of ERK and JNK-p38 MAP kinases on apoptosis. Science 270: 1326-1331, 1995.

30. Johnson GL and Lapadat R: Mitogen-activated protein kinase pathways mediated by ERK, JNK, and p38 protein kinases. Science 298: 1911-1912, 2002.

31. Neff L, Zeisel M, Druet V, Takeda K, Klein JP, Sibilia J and Wachsmann D: ERK 1/2- and JNKs-dependent synthesis of interleukins 6 and 8 by fibroblast-like synoviocytes stimulated with protein I/II, a modulin from oral streptococci, requires focal adhesion kinase. J Biol Chem 278: 27721-27728, 2003.

32. Han Z, Boyle DL, Chang L, et al: c-Jun N-terminal kinase is required for metalloproteinase expression and joint destruction in inflammatory arthritis. J Clin Invest 108: 73-81, 2001.

33. Hammaker D, Sweeney S and Firestein GS: Signal transduction networks in rheumatoid arthritis. Ann Rheum Dis 62: 86-89, 2003.

34. Morel J and Berenbaum F: Signal transduction pathways: new targets for treating rheumatoid arthritis. Joint Bone Spine 71: 503-510, 2004.

35. Yen ML, Su JL, Chien CL, et al: Diosgenin induces hypoxiainducible factor- 1 activation and angiogenesis through estrogen receptor-related phosphatidylinositol 3-kinase/Akt and p38 mitogen-activated protein kinase pathways in osteoblasts. Mol Pharmacol 68: 1061-1073, 2005.
36. Kim KW, Cho ML, Park MK, Yoon CH, Park SH, Lee SH and Kim HY: Increased interleukin-17 production via a phosphoinositide 3-kinase/Akt and nuclear factor kappaB-dependent pathway in patients with rheumatoid arthritis. Arthritis Res Ther 7: R139-R148, 2005.

37. Shishodia S and Aggarwal BB: Diosgenin inhibits osteoclastogenesis, invasion, and proliferation through the downregulation of Akt, IkappaB kinase activation and NF-kappaB-regulated gene expression. Oncogene 25: 1463-1473, 2006.

38. Martel-Pelletier J, Pelletier JP and Fahmi H: New insights into prostaglandin biology. J Rheumatol 31: 14-16, 2004.

39. Liagre B, Vergne P, Rigaud M and Beneytout JL: Arachidonate 15-lipoxygenase of reticulocyte-type in human rheumatoid arthritis type B synoviocytes and modulation of its activity by proinflammatory cytokines. J Rheumatol 26: 1044-1051, 1999.

40. Crofford LJ, Wilder RL, Ristimaki AP, Sano H, Remmers EF, Epps HR and Hla T: Cyclooxygenase- 1 and -2 expression in rheumatoid synovial tissues. Effects of interleukin-1 beta, phorbol ester, and corticosteroids. J Clin Invest 93: 1095-1101, 1994

41. Kemick ML, Chin JE and Wuthier RE: Role of prostaglandins in differentiation of growth plate chondrocytes. Adv Prostaglandin Thromboxane Leukot Res 19: 423-426, 1989.

42. Pelletier JP, Fernandes JC, Jovanovic DV, Reboul P and MartelPelletier J: Chondrocyte death in experimental osteoarthritis is mediated by MEK $1 / 2$ and p38 pathways: role of cyclooxygenase- 2 and inducible nitric oxide synthase. J Rheumatol 28: 2509-2519, 2001

43. Jovanovic DV, Mineau F, Notoya K, Reboul P, Martel-Pelletier J and Pelletier JP: Nitric oxide induced cell death in human osteoarthritic synoviocytes is mediated by tyrosine kinase activation and hydrogen peroxide and/or superoxide formation. J Rheumatol 29: $2165-2175,2002$

44. Shan ZZ, Masuko-Hongo K, Dai SM, Nakamura H, Kato T and Nishioka K: A potential role of 15 -deoxy-delta(12,14)-prostaglandin $\mathrm{J} 2$ for induction of human articular chondrocyte apoptosis in arthritis. J Biol Chem 279: 37939-37950, 2004.

45. Relic B, Benoit V, Franchimont N, et al: 15-deoxy-delta12,14prostaglandin J2 inhibits Bay 11-7085-induced sustained extracellular signal-regulated kinase phosphorylation and apoptosis in human articular chondrocytes and synovial fibroblasts. J Biol Chem 279: 22399-22403, 2004.

46. Tanioka T, Nakatani Y, Semmyo N, Murakami M and Kudo I: Molecular identification of cytosolic prostaglandin E2 synthase that is functionally coupled with cyclooxygenase- 1 in immediate prostaglandin E2 biosynthesis. J Biol Chem 275: 32775-32782, 2000

47. Fahmi H: mPGES-1 as a novel target for arthritis. Curr Opin Rheumatol 16: 623-627, 2004.

48. Kojima F, Naraba H, Sasaki Y, Beppu M, Aoki H and Kawai S: Prostaglandin E2 is an enhancer of interleukin-1beta-induced expression of membrane-associated prostaglandin E synthase in rheumatoid synovial fibroblasts. Arthritis Rheum 48: 2819-2828, 2003.

49. Westman M, Korotkova M, Af Klint E, et al: Expression of microsomal prostaglandin $\mathrm{E}$ synthase 1 in rheumatoid arthritis synovium. Arthritis Rheum 50: 1774-1780, 2004.

50. Korotkova M, Westman M, Gheorghe KR, et al: Effects of antirheumatic treatments on the prostaglandin E2 biosynthetic pathway. Arthritis Rheum 52: 3439-3447, 2005. 